\title{
Tbr2 Is Required to Generate a Neural Circuit Mediating the Pupillary Light Reflex
}

\author{
Neal T. Sweeney, Hannah Tierney, and David A. Feldheim \\ Department of Molecular, Cell, and Developmental Biology, University of California, Santa Cruz, California 95064
}

\begin{abstract}
There are $\sim 20$ types of retinal ganglion cells (RGCs) in mice, each of which has distinct molecular, morphological, and physiological characteristics. Each RGC type sends axon projections to specific brain areas that execute light-dependent behaviors. Here, we show that the T-box transcription factor Tbr2 is required for the development of several RGC types that participate in non-image-forming circuits. These types are molecularly distinct, project to non-image-forming targets, and include intrinsically photosensitive RGCs. Tbr2 mutant mice have reduced retinal projections to non-image-forming nuclei and an attenuated pupillary light reflex. These data demonstrate that Tbr2 acts to execute RGC type choice and/or survival in a set of RGCs that mediates light-induced subconscious behaviors.
\end{abstract}

Key words: axon projections; retina; TBR2; visual circuit

\section{Introduction}

There are thousands of neuronal types in the CNS with different morphologies, intrinsic properties, and connection patterns (Nelson et al., 2006; Luo et al., 2008; Masland, 2012). Derived from a common progenitor pool, each neuronal type uses a combination of transcriptional regulation and environmental cues to express a set of genes critical for inclusion into specific circuits. A long-standing goal in neuroscience has been to complete the link between a neuron's transcriptional profile, its integration in a neural circuit, and that circuit's contribution to behavior.

Visual processing in the retina is accomplished by parallel circuits composed of connections between the six retinal neuron classes (Wässle, 2004). At the output of each retinal circuit is one of $\sim 20$ retinal ganglion cells (RGC) types that can be classified by morphological, molecular, and functional criteria. Each RGC type also participates in distinct retinal circuits and projects to a specific set of targets in the brain (Coombs et al., 2007; Berson, 2008; Schmidt et al., 2011).

Light-evoked behaviors can be divided broadly into those controlled by image-forming or non-image-forming circuits, and different behaviors are thought to be served by different RGC types (Chalupa and Günhan, 2004; Fu et al., 2005). For example, many types of ON, OFF, and ON-OFF direction-selective RGCs

\footnotetext{
Received Jan. 4, 2014; revised March 7, 2014; accepted March 12, 2014.

Author contributions: N.T.S. and D.A.F. designed research; N.T.S. and H.T. performed research; N.T.S., H.T., and D.A.F. analyzed data; N.T.S. and D.A.F. wrote the paper.

This work was supported by the National Institutes of Health Grant R01EY022117 to D.A.F.), the Glaucoma Research Foundation (D.A.F.), California Institute of Regenerative Medicine (Postdoctoral Scholar Training Fellowship TG2-01157 to N.T.S. and Major Facilities Grant FA1-00617-1 to the UCSC). We thank Jena Yamada for technical support, Andy Huberman for sharing GFP-labeled mice strains, and members of the Feldheim and Sher laboratories for critical reading of the manuscript.

The authors declare no competing financial interests.

Correspondence should be addressed to David A. Feldheim, Professor, Department of Molecular, Cell, and Developmental Biology, University of California, 1156 High Street, Santa Cruz, CA 95064. E-mail: feldheim@biology.ucsc.edu.

DOI:10.1523/JNEUROSCI.0035-14.2014

Copyright (C) 2014 the authors $\quad 0270-6474 / 14 / 345447-07 \$ 15.00 / 0$
}

project only to the dorsal lateral geniculate nucleus (dLGN) and superior colliculus (SC), areas involved in image-forming circuits that determine the "where" and "what" of the visual scene. Other RGC types, including intrinsically photosensitive RGCs (ipRGCs), project to a number of non-image-forming areas (Berson et al., 2002; Hattar et al., 2002; Provencio et al., 2002; Ecker et al., 2010) that are involved in reflexive or subconscious visual behaviors such as day/night activity cycles, the pupillary light reflex, and image stabilization.

Much of RGC type-specific morphology and functionality is established before eye opening in mice. Therefore, differentiation from progenitor cells is significantly influenced by the regulated expression of transcription factors (Shirasaki and Pfaff, 2002). Numerous transcription factors, many of which control cell fate in the nervous system and elsewhere, are expressed in RGCs (Brown et al., 2001; Mu and Klein, 2004; Badea et al., 2009; Jiang et al., 2013), although none have been linked directly to specific RGC functional types and accompanying neural circuits. Here, we show that Tbr2 (also known as Eomesodermin), a T-box transcription factor that plays a critical role in the development of neural and non-neural tissues (Russ et al., 2000; Arnold et al., 2008; Mao et al., 2008; Sessa et al., 2008), is essential for the specification of RGC types that participate in non-imageforming visual circuits. We show that Tbr2 is expressed selectively in a functional subset of RGCs that includes ipRGCs and several other types that innervate non-image-forming visual brain targets. Removal of Tbr2 from the developing retina results in decreased retinal projections specifically to non-imageforming areas and an attenuated pupillary light reflex. Together, these results demonstrate that Tbr2 is an essential part of the transcription factor code required for the specification of nonimage-forming RGC types.

\section{Materials and Methods}

Mice. Cadherin3-GFP, CB2-GFP, and DRD4-GFP mice were genotyped as described previously (Huberman et al., 2008, 2009; Osterhout et al., 2011). Cryopreserved sperm from Tbr2-GFP transgenic mice (stock no. 
011151-UCD) was obtained from the Mutant Mouse Regional Resource Center and in vitro fertilization was performed at the University of California-Santa Cruz (UCSC). Positive transgenic mice were determined by PCR of tail DNA using primers against GFP (5'-CCTACGGCGTGCAGTGCTTCAGC-3' and 5'-CGGCGAGCTGCACGCTGCGTCCTC3'). The Tbr2 floxed mouse line (stock no. 017293) and Calbindin-2-Cre line (stock no. 010774) were acquired from The Jackson Laboratory. Genotyping for Tbr2 was done with the following oligonucleotide primers: (5'-AGATGGAAATTTGGGAATGAA-3') and (5'-GGCTACTACGGCCTGAAAC- $3^{\prime}$ ) and genotyping for Cre was done using the following oligonucleotide primers: (5' -ACCAGAGACGGAAATCCATCG-3' and 5'-TGCCACGACCAAGTGACAGCAATG-3'). All procedures were performed in accordance with the UCSC Institutional Animal Care and Use Committee.

Immunohistochemistry. Postnatal mice of both sexes were killed and intracardially perfused with ice-cold PBS, followed by ice-cold 4\% PFA (in PBS, pH 7.4). Eyes were dissected out of the head and fixed in $4 \%$ PFA for $30 \mathrm{~min}$ at room temperature. For whole-mount preparations, the retina was dissected out of the eye and placed in blocking buffer $(10 \%$ serum, $0.25 \%$ Triton X-100 in PBS) for $1 \mathrm{~h}$ at room temperature. For cryosectioning, the lens and vasculature were removed and the retina was sunk in $30 \%$ sucrose overnight at $4^{\circ} \mathrm{C}$. Retinas were then embedded in Tissue-Tek OCT Compound (Sakura Finetek) on dry ice and stored at $-80^{\circ} \mathrm{C}$. Next, $18 \mu \mathrm{m}$ sections were cut on a CM1520 Cryostat (Leica Microsystems) at $-20^{\circ} \mathrm{C}$ and collected on histology-grade glass slides. Sections were dried overnight at room temperature, rehydrated in PBS, and blocked in blocking buffer for $1 \mathrm{~h}$ at room temperature.

The following antibodies were diluted at 1:1000 in blocking buffer and incubated overnight at $4^{\circ} \mathrm{C}$ : GFP rabbit polyclonal (Invitrogen), GFP chicken polyclonal (Aves Labs), Tbr2 rabbit polyclonal (Abcam), Tbr2 chicken polyclonal (Lifespan), GABA rabbit polyclonal (Sigma), Unc5d mouse monoclonal (Abcam), Brn3a goat polyclonal (Santa Cruz Biotechnology), melanopsin rabbit polyclonal (Advanced Targeting Systems), and CART rabbit polyclonal (Phoenix Pharmaceuticals). The following day, retinas or sections were washed in PBS at room temperature and incubated with appropriate fluorescently conjugated secondary antibodies diluted at 1:1000 in blocking buffer for $1 \mathrm{~h}$. Retinas and sections were washed again and a coverslip was mounted using Fluoromount G (Southern Biotechnology). Imaging was performed with an Olympus BX51 epifluorescent microscope equipped with QImaging Retiga EXi digital camera or a Leica Wide-field DM5500. Retinas from two or more mice were used for each experiment.

Axon tracing. To label all RGC axons, mice of both sexes were anesthetized by subcutaneous injection of ketamine/xylazine solution (100 and $10 \mathrm{mg} / \mathrm{kg}$, respectively). Then, $1 \mu \mathrm{l}$ of CTB-555 (2 mg/ml in PBS) was injected using a pulled glass micropipette and Picospritzer III set at $\sim 30$ psi and $\sim 15 \mathrm{~ms}$ pulse duration. After $2-3 \mathrm{~d}$, mice were intracardially perfused with PBS and PFA and brains were dissected out, fixed overnight in 4\% PFA, and then cryopreserved overnight in 30\% sucrose, both at $4^{\circ} \mathrm{C}$. Coronal sections were cut at $50 \mu \mathrm{m}$ with an HM430 sliding microtome (Thermo Fisher) and immunostaining for GFP was performed as described using the same protocol as that used for wholemount retinas. Retinorecipient areas were defined using anatomical landmarks and mean fluorescence intensity was calculated using Adobe Photoshop.

Pupillary light response behavior. To measure the pupillary light response, mice of both sexes were dark adapted for 1 min under infrared illumination. Still under infrared illumination, mice were filmed using a Sony Handycam DCR-HC96 for $10 \mathrm{~s}$ to obtain a baseline reading, followed by exposure of $460 \mathrm{~nm}$ LED light to the contralateral or ipsilateral eye for $30 \mathrm{~s}$ at the high-light condition $\left(2.9 \mathrm{~mW} / \mathrm{cm}^{2}\right)$, followed by $1 \mathrm{~min}$ in darkness, then $30 \mathrm{~s}$ of exposure at the low-light condition $\left(172 \mathrm{~mW} / \mathrm{cm}^{2}\right)$. Light levels were controlled using neutral density filters. This protocol was repeated three times, giving three readings per mouse at each light level. Movies were converted into still photos using Apple iMovie and the percent of pupil constriction was calculated using ImageJ.

\section{Results}

\section{Tbr2 is expressed in a subset of RGC types that project to non-image-forming areas}

To identify transcriptional regulators involved in RGC type choice or maintenance, we screened a panel of transcription factor antibodies for those expressed in RGC subsets in the developing or mature retina. Consistent with previous results (Mao et al., 2008), we found that Tbr2 is expressed in $\sim 10 \%$ of cells in the ganglion cell layer and a small number in the inner nuclear layer of the postnatal day $8(\mathrm{P} 8)$ retina (Fig. $1 A$ ). Nearly all Tbr $2^{+}$cells were RGCs, because only $3 \%$ of Tbr $2^{+}$cells also expressed the displaced amacrine cell marker GABA (Pérez De Sevilla Müller et al., 2007; Fig. 1C). However, very few Tbr ${ }^{+}$cells were labeled by a Brn3a antibody (Fig. 1A, B, Table 1), which marks $\sim 80 \%$ of RGCs (Xiang et al., 1995).

Based on the number of Tbr $2^{+}$RGCs, we hypothesized that these were not a single RGC type, but rather a collection of types that share common features. To test this idea, we determined the degree of overlap between Tbr2 expression and markers of defined RGC types. In one set of experiments, we examined coexpression of Tbr2 in transgenic BAC lines that express GFP in defined RGC types. These include DRD4-GFP and CB2-GFP, in which GFP is expressed in posterior-direction-selective RGCs (Huberman et al., 2009) and $\alpha$ OFF-transient RGCs (Huberman et al., 2008), respectively. Both DRD4-GFP and CB2-GFP lines label RGCs with axons that selectively target two image-forming areas, the SC and dLGN. We also examined the Cadherin-3-GFP BAC line (Cdh3-GFP), in which GFP is expressed in several RGC types that all project to non-image-forming areas (Osterhout et al., 2011). Notably, we found that Tbr2 is expressed in nearly all Cdh3-GFP RGCs, but in only a small percentage of DRD4-GFP RGCs and CB2-GFP RGCs (Fig. 1D-F, Table 1).

Intrinsically photosensitive RGCs are a major class of RGCs that send axons to non-image-forming areas and this class can be subdivided into at least six different subtypes consisting of

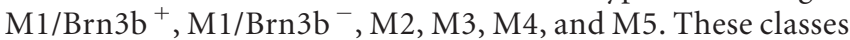
differ from each other in their expression levels of Brn3b and melanopsin (M1-M3 have high melanopsin expression, whereas M4-M5 have melanopsin expression that is undetectable using immunocytochemistry), dendritic arborization patterns (either ON or OFF sublamina of the inner plexiform layer [IPL]), axonal targeting, and physiological response properties (Schmidt et al., 2011). We found that $91 \%$ of melanopsin-positive RGCs were also labeled by Tbr2 antibodies (Fig. 1G).

Tbr2 was also found to be expressed in only 9\% of RGCs that express the ON-OFF direction-selective RGC marker CART (Fig. $1 I)$ and by only of $5 \%$ of Isl $2^{+}$RGCs $(n=136$; Fig. $2 A)$, both of which project selectively to image-forming targets (Pak et al., 2004; Triplett et al., 2014). Table 1 summarizes the Tbr2 antibody-staining results and demonstrates that the vast majority of RGCs in each subset examined express Tbr2 or Brn3a, but not both. Together, these data show that Tbr2 is expressed in RGC types that send axonal projections specifically to non-imageforming areas and suggest that it may be an upstream activator of genes required for the development and function of non-imageforming circuits such as melanopsin.

\section{Tbr2-positive RGCs include several subclasses}

In addition to the $18 \%(n=157$ cells $)$ of Tbr $2^{+}$RGCs that express melanopsin and the $9 \%(n=505$ cells $)$ that express Cdh3-GFP, we found that $20 \%(n=366$ cells $)$ of Tbr ${ }^{+}$cells express the Netrin receptor Unc5d (Fig. $1 H$ ). Unc5d ${ }^{+}$RGCs 

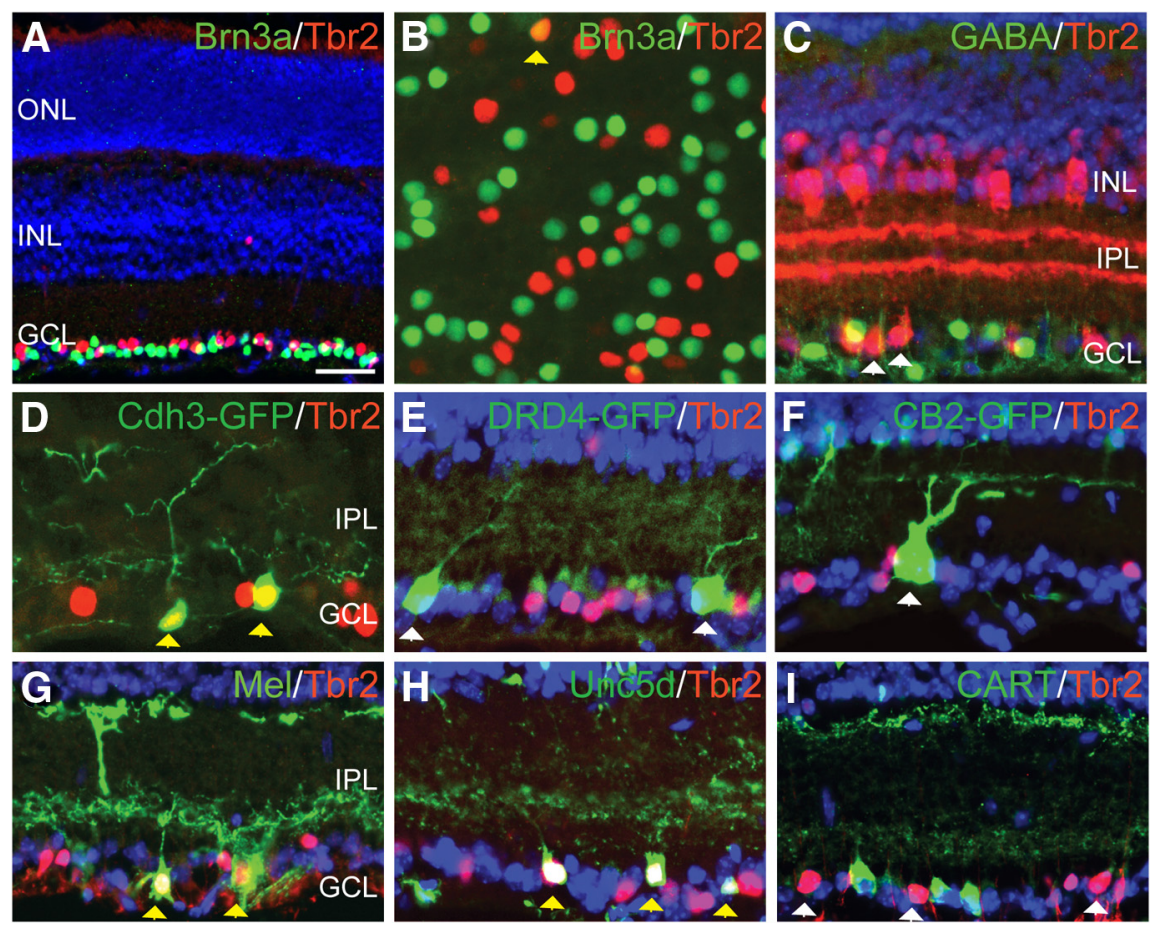

Figure 1. Tbr2 is expressed in a distinct subset of RGCs. Sections through P8 eyes were immunostained with the antibodies indicated; the color of the text matches the color of the label. Blue is DAPI, showing the location of retinal nuclei, and a GFP antibody was used to increase signal. Few Tbr2 ${ }^{+}$RGCs express Brn3a $(2.4 \%, n=3235$ cells; $\boldsymbol{A}, \boldsymbol{B}), \mathrm{GABA}(3 \%, n=96$ cells; $\boldsymbol{C}$ ), DRD4-GFP $(12 \% ; n=75$ cells; $\boldsymbol{E})$, CB2-GFP $(3 \% ; n=30$ cells; $\boldsymbol{F})$, or CART (9\%; $n=80$ cells; $\boldsymbol{I})$. However, most Cdh3-GFP $(98 \% ; n=44$ cells; D), Melanopsin ${ }^{+}(91 \% ; n=32$ cells; $\boldsymbol{G})$, and Unc5 ${ }^{+}(68 \% ; n=107$ cells; $\boldsymbol{H})$ RGCs also express Tbr2. $\boldsymbol{B}$ shows a flat-mounted retina, $\mathrm{RGC}$ side up. Yellow arrowheads indicate examples of $\mathrm{Tbr}^{+}{ }^{+}$cells that are colabeled with the indicated marker. White arrowheads indicate examples of Tbr2 ${ }^{+}$cells that are not colabeled. ONL, Outer nuclear layer; IPL, inner plexiform layer; INL, inner nuclear layer; $\mathrm{GCL}$, ganglion cell layer. Scale bars: $\boldsymbol{A}, 50 \mu \mathrm{m} ; \boldsymbol{B}-\mathbf{I}, 25 \mu \mathrm{m}$.

Table 1. Summary of RGC marker coexpression with Tbr2 and Brn3a antibodies

\begin{tabular}{lcc}
\hline & \multicolumn{1}{c}{ Coexpression $(n)$} & \\
\cline { 2 - 3 } & Tbr2 & Brn3a \\
\hline CB2-GFP & $3 \%(30)$ & $100 \%(30)$ \\
Cdh3-GFP & $98 \%(44)$ & $8 \%(132)$ \\
DRD4-GFP & $12 \%(75)$ & $94 \%(33)$ \\
IsL2-GFP & $5 \%(136)$ & $94 \%^{a}$ \\
CART & $9 \%(80)$ & $98 \%(89)$ \\
Melanopsin & $91 \%(32)$ & $0 \%(50)$ \\
Unc5d & $68 \%(107)$ & $0 \%(20)$ \\
\hline
\end{tabular}

${ }^{a}$ Triplett et al., 2014.

have dendrites that are restricted to the ON sublamina of the IPL (adjacent to the lamina where melanopsin-positive RGCs arborize) and very few coexpress melanopsin or are labeled by Cdh3-GFP (Fig. $2 B, C$ ). Therefore, there are several nonoverlapping types of RGCs within the Tbr ${ }^{+}$pool, including those labeled by a melanopsin antibody (M1-M3 types), Cad3-GFP RGCs, and Unc5d ${ }^{+}$RGCs (Fig. 2I).

\section{Tbr2-positive RGCs project primarily to non-image-forming} areas

To determine the dendritic and axonal projections of Tbr $2^{+}$ RGCs, we obtained a Tbr2-GFP transgenic mouse line from GENSAT (Gong et al., 2003). In these mice, GFP is expressed in the cell soma, axons, and dendrites of Tbr ${ }^{+}$RGCs. Costaining of Tbr2-GFP retinas with antibodies directed against GFP and Tbr2 shows that all Tbr2-GFP cells also express Tbr2 protein, but only $6 \%$ of Tbr2 antibody-labeled cells expressed GFP (Fig. 2G). The
Tbr2-GFP population is enriched for melanopsin $^{+} /$Tbr ${ }^{+}$types (Fig. $2 H$ ) and has a range of morphological features such as cell soma size and dendritic lamination patterns; most have dendrites restricted to the ON sublamina of the IPL, with occasional projections to outermost OFF layer (Fig. 2D,E). From this analysis, we conclude that the Tbr2-GFP expression in this mouse serves as a reliable marker of $\mathrm{Tbr}^{+}$RGCs, including melanopsin ${ }^{+}$ RGCs, but also likely underrepresents the

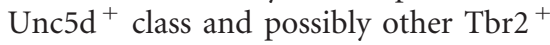
RGC types.

In Figure 3, we compare the projection patterns of all contralateral RGCs with those labeled in the Tbr2-GFP line. We find that the vast majority of Tbr2-GFP ${ }^{+}$ axons project to several areas in the brain that mediate non-image-forming functions, including the olivary pretectal nucleus (OPN; Fig. $3 A-C$ ), posterior pretectal nucleus (PPN; Fig. $3 G-I$ ), intergeniculate leaflet (IGL), and ventral lateral geniculate nucleus (vLGN; Fig. 3D-F). The OPN is required for the pupillary light reflex (Güler et al., 2007) and the vLGN and IGL are involved in day-night activity cycles (Harrington, 1997; Schmidt et al., 2011). The precise role of the PPN is not known, but it likely contributes to oculomotor control (Giolli et al., 2006). Conversely, the image-forming areas, SC (Fig. $3 N, O$ ) and dLGN (Fig. 3D-F), only receive a few sparse connections. There are no Tbr2-GFP ${ }^{+}$axons found in the SCN, which controls circadian entrainment, nor in two areas thought to be involved in image stabilization, the nucleus of the optic tract (NOT; Fig. 3G-I) and the medial temporal nucleus (MTN; Fig. 3 L, M; Giolli et al., 2006; Dhande et al., 2013). Although we cannot rule out that Tbr ${ }^{+}$RGCs not labeled in the Tbr2-GFP line target these areas, this pattern of projections suggests that Tbr2 ${ }^{+}$RGCs target a specific subset of non-imageforming nuclei.

\section{Tbr2 is required for the development of Tbr2-positive RGC types}

It has been shown previously that removing Tbr2 from retinal progenitors leads to an increase in RGC death during retinal development, but whether this death was restricted to a specific RGC type or types was not determined (Mao et al., 2008). To determine whether the RGC types used in non-image-forming circuits require Tbr2 during retinal development, we crossed a mouse containing a floxed allele of Tbr2 (Zhu et al., 2010) with a mouse that expresses Cre behind the Calbindin-2 promoter (CB2-Cre). Crossing a ROSA26-lox-stop-lox-tdTomato reporter line to the CB2-Cre line reveals that, at P8, 56\% of Tbr ${ }^{+}$RGCs are positive for the Cre reporter (Fig. $2 F$ ). By comparing the expression pattern of control and $\mathrm{Tbr} 2^{\mathrm{fl} / \mathrm{fl}} ; \mathrm{CB} 2^{\mathrm{Cre} /+}$ retinas, we find that the number of Tbr2 ${ }^{+}$cells in the ganglion cell layer

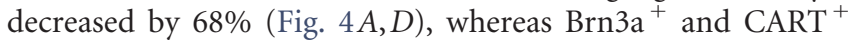
RGCs were unchanged (Fig. $4 C, F$ ). Among the Tbr $2^{+}$RGCs that remained, very few were Cdh3-GFP RGCs (98\% decrease) or Unc5d $^{+}$(90\% decrease); Melanopsin ${ }^{+}$RGCs also decreased by 

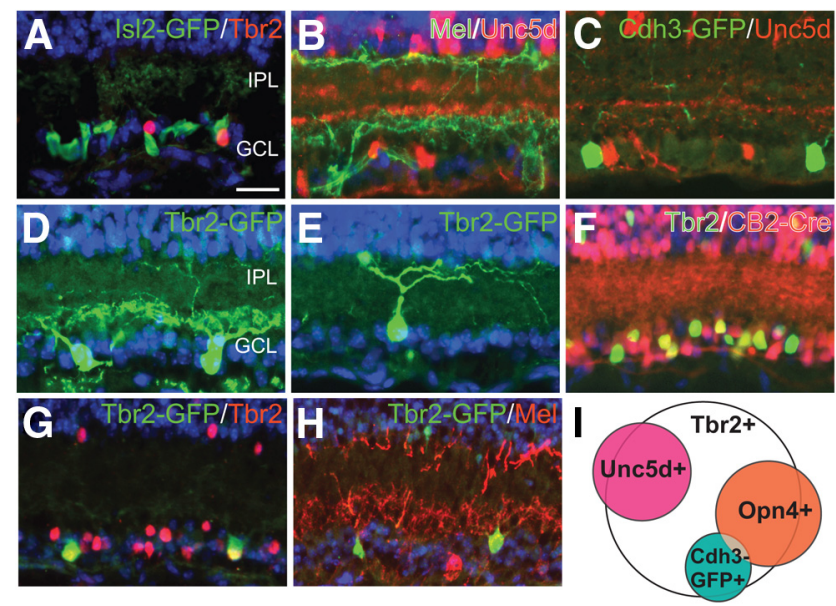

Figure 2. Tbr2 is expressed in at least three largely nonoverlapping sets of RGCs. Panels are labeled as in Figure 1. Tbr2 does not colocalize with IsI2-GFP, which projects to image-forming areas $(5 \% ; n=136$ cells; $A)$, and few cells show coincident expression of Melanopsin and Unc $5 \mathrm{~d}$ $(1.5 \% ; n=67$ cells; $\boldsymbol{B})$ or Cdh3-GFP and Unc5d (0\%; $n=44$ cells; $)$. Tbr2-GFP lamination patterns show that many labeled cells project to the inner $0 \mathrm{~N}$ sublamina $(\boldsymbol{D})$ with a few projecting to the outer OFF lamina $(\boldsymbol{D}, \boldsymbol{E})$. A majority of Tbr2 ${ }^{+}$cells were labeled by $\mathrm{CB} 2-\mathrm{Cre}(56 \% ; n=$ 116 cells; $\boldsymbol{F})$ and, although all Tbr2-GFP ${ }^{+}$cells express Tbr2 $(100 \% ; n=50$ cells; $\boldsymbol{G})$, and a majority express melanopsin $(76 \% ; n=62$ cells; $\boldsymbol{H})$, only $6 \%(n=765)$ of Tbr2 ${ }^{+} \mathrm{RGCs}$ are labeled by Tbr2-GFP. I is a diagram showing the degree of coexpression of Tbr2 ${ }^{+} \mathrm{RGC}$ subclasses. GCL, Ganglion cell layer; IPL, inner plexiform layer. Scale bar, $25 \mu \mathrm{m}$.

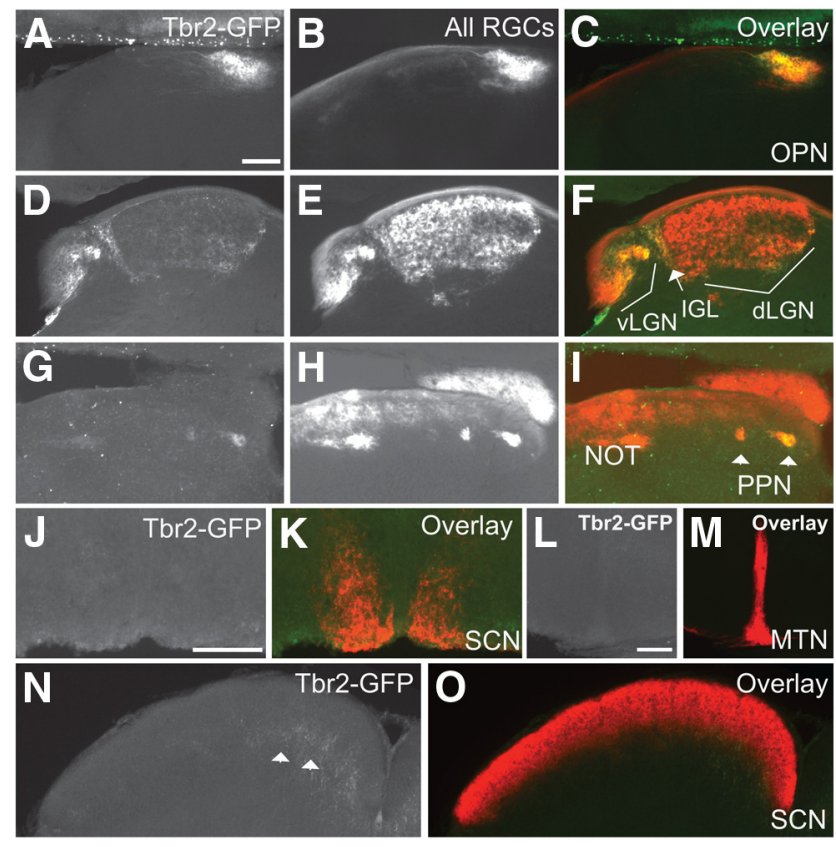

Figure 3. Tbr2-GFP labels axons that project to a subset of the non-image-forming retinorecipient areas of the brain. Sections through an adult (P20) mouse brain show Tbr2-GFP labeled $(\boldsymbol{A}, \boldsymbol{D}, \boldsymbol{G}, \boldsymbol{J}, \boldsymbol{L}, \boldsymbol{N})$ and all contralateral eye inputs $(\boldsymbol{B}, \boldsymbol{E}, \boldsymbol{H})$ in different retinorecipient areas. Merged images are shown in $\boldsymbol{C}, \boldsymbol{F}, \boldsymbol{I}, \boldsymbol{K}, \boldsymbol{M}$, and $\boldsymbol{O}$. The retinorecipent areas shown are as follows: OPN $(\boldsymbol{A}-\boldsymbol{C}) ; \mathrm{VLGN}, \mathrm{IGL}$, and dLGN (D-F); NOT and PPN $(\boldsymbol{G}-\boldsymbol{I}), \operatorname{SCN}(\boldsymbol{J}, \boldsymbol{K}), \operatorname{MTN}(\boldsymbol{L}, \boldsymbol{M})$, and SC $(\boldsymbol{N}$, 0 ). Arrowheads in $N$ show sparse, GFP-positive axons in the deep SC. Each of five mice examined shared the same projection patterns. Scale bars, $100 \mu \mathrm{m}$ for all panels.

$79 \%$ (Fig. $4 A, B, D, E$ ). Interestingly, the melanopsin ${ }^{+}$RGCs that remain have dendritic arborizations restricted to the OFF sublaminae of the IPL, whereas those that normally arborize in the ON sublaminae are missing (Fig. 4B,E). Because M1 ipRGCs form the only melanopsin ${ }^{+}$ipRGC class with dendrites that
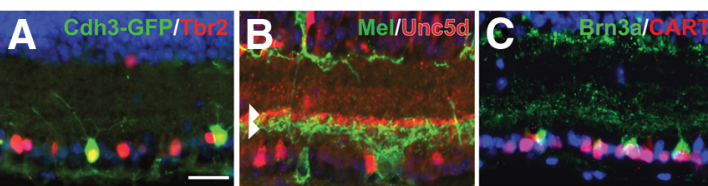

Control
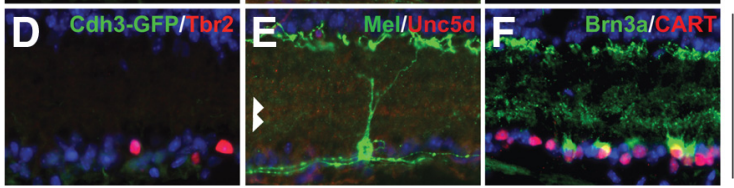

Tbr2 $2^{\mathrm{FI} / \mathrm{FI}}$

$\mathrm{CB} 2^{\mathrm{Cre} /+}$

Figure 4. Conditional deletion of $\mathrm{Tbr} 2$ using $\mathrm{CB2}$-Cre leads to the loss of $\mathrm{Tbr} 2^{+} \mathrm{RGCS}$. Sections through P8 littermate control $(\boldsymbol{A}-\boldsymbol{C})$ and $\mathrm{Tbr} 2^{\mathrm{fl} / \mathrm{fl}} ; \mathrm{CB} 2^{\mathrm{Cre} /+}(\boldsymbol{D}-\boldsymbol{F})$ retinas. Tbr2 ${ }^{+}$cells are reduced by $68 \%$ in the Tbr2 mutant (WT: $194.4 /$ section, $n=8$ sections; K0: 61.4/section, $n=$ 12 sections) and Unc5 $\mathrm{d}^{+}$(Control: $40 /$ section, $n=5$ sections; K0:3.9/section, $n=10$ sections) and melanopsin ${ }^{+}$RGCs (Control: 33/section, $n=3$ sections; K0: $6.8 /$ section, $n=6$ sections) are also reduced and staining in the inner $0 \mathrm{~N}$ sublaminae is missing (white arrowheads; $\boldsymbol{B}, \boldsymbol{E}$ ). The numbers of Brn3a ${ }^{+}$(Control: $423 /$ section, $n=3$ sections; $\mathrm{KO}: 467 /$ section, $n=3$ sections) and CART ${ }^{+}$(Control: $94 /$ section, $n=3$ sections; K0: $88 /$ section, $n=3$ sections;) cells are not significantly different between controls and Tbr2 mutants $(\boldsymbol{C}, \boldsymbol{F})$. Arrowheads in $\boldsymbol{B}$ and $\boldsymbol{E}$ show the location of melanopsin ${ }^{+}$- and Unc5 $\mathrm{d}^{+}$dendrites in $\mathrm{ON}$ sublimae in controls and conditional mutants. Retinas from 3 mice of each genotype were used. Scale bar, $25 \mu \mathrm{m}$.
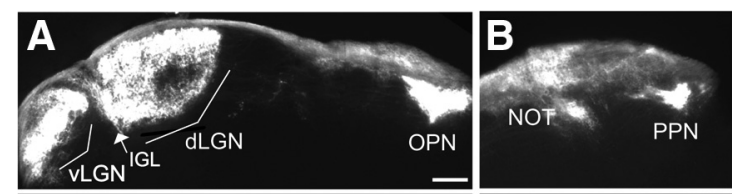

Control
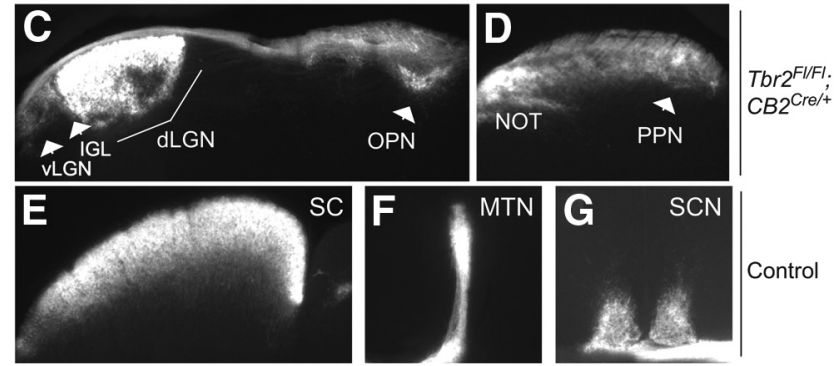
$\mathrm{CB} 2^{\mathrm{Cre} /+}$
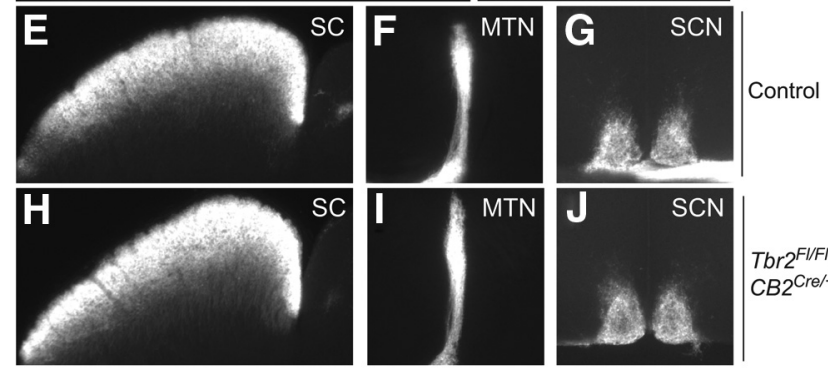

Tbr2 $2^{\text {FIFI }}$ $\mathrm{CB} 2^{\mathrm{Cre} /+}$

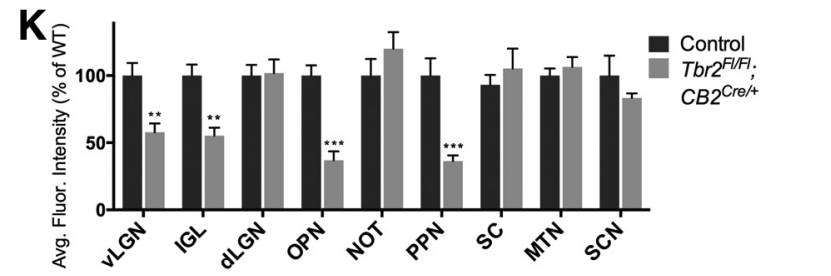

Figure 5. Tbr2 mutants show decreased axonal projections to non-image-forming areas Axon tracing of the contralateral eye with $\mathrm{CtB}-555$ in control $(\boldsymbol{A}, \boldsymbol{B}, \boldsymbol{E}, \boldsymbol{F}, \boldsymbol{G})$ and $\mathrm{Tbr} 2^{\mathrm{fl} / \mathrm{fl}} ; \mathrm{CB}^{\mathrm{Cre} /+}$ mice $(\boldsymbol{C}, \boldsymbol{D}, \boldsymbol{H}, \boldsymbol{I}, \boldsymbol{J})$ was used to visualize projections to the retinorecipient areas labeled. Tbr2 mutant mice have decreased total retinal projections to the vLGN, IGL, OPN, and PPN (yellow arrowheads) but not to the dLGN, NOT, SC MTN or SCN. Scale bar, $100 \mu \mathrm{m}$. Fluorescence intensity was calculated for each target region ( $n=3-5$ mice; $\boldsymbol{K}$ ) and significant was calculated using $t$ tests. ${ }^{* *} p<0.05 ;{ }^{* * *} p<0.01$. $p$-values are as follows: vLGN $=0.043 ; \mathrm{IGL}=0.049$; $\mathrm{dLGN}=0.3162 ; \mathrm{OPN}=0.0006 ; \mathrm{NOT}=0.636 ; \mathrm{PPN}=0.008 ; \mathrm{SC}=0.254, \mathrm{MTN}=0.585$, and $\mathrm{SCN}=0.386$.

stratify exclusively in the OFF sublamina, we conclude that the CB2-Cre line removes Tbr2 from at least the M2 and M3 classes of ipRGCs, likely via apoptotic cell death, as was found previously (Mao et al., 2008). We could not assess whether the number of 


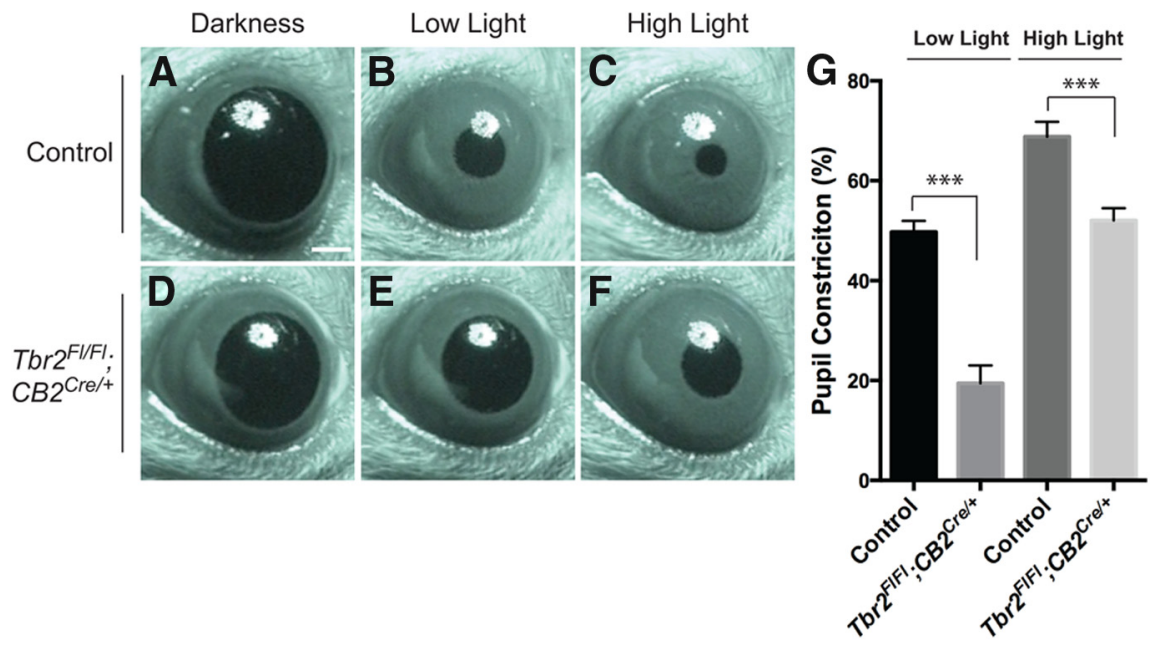

Figure 6. Pupillary light reflex in Tbr2 mutants is attenuated. $\boldsymbol{A}-\boldsymbol{F}$, Adult control or $T b r 2^{f / f f} ; C B 2^{(\text {re/ } /+}$ mice were dark adapted for $1 \mathrm{~min}$ and then either low $\left(172 \mathrm{~mW} / \mathrm{cm}^{2}\right)$ or high $\left(2.9 \mathrm{~mW} / \mathrm{cm}^{2}\right)$ light intensity was presented for $30 \mathrm{~s} \mathrm{to} \mathrm{the} \mathrm{contralateral} \mathrm{eye} \mathrm{and}$ monitored with an infrared camera. $\mathbf{G}$, Graph showing the percent pupil constriction in control and Tbr2 mutant mice ( $n=6$ of each) and a significant decrease in response of the mutant at both light intensities. Using one-way ANOVA, $p=0.00014$ for high light and $p=2.2 \times 10^{-8}$ for low light. ${ }^{* * *} p<0.001$. Scale bar, $500 \mu \mathrm{m}$.

M4 and M5 ipRGC types are reduced in the mutant because they are not labeled with the melanopsin antibody and there is currently no molecular marker that identifies them (Ecker et al., 2010).

\section{Tbr2 is required for the formation of retinal projections to non-image-forming nuclei}

Consistent with the loss of most melanopsin ${ }^{+}, \mathrm{Cdh} 3-\mathrm{GFP}$, and $\mathrm{Unc} \mathrm{d}^{+} \mathrm{RGCs}, \mathrm{Tbr} 2^{f l f l} ; \mathrm{CB} 2^{\mathrm{Cre} /+}$ mice have severely reduced innervation of a subset of non-image-forming brain nuclei. We traced and quantified contralateral eye projections to the brain of P15-P20 Tbr2 ${ }^{f l f l} ; C B 2^{C r e /+}$ mice and control littermates and compared the RGC projection patterns in coronal brain sections $(n=$ 5 mice of each genotype). Tbr2 mutant retinas exhibited reduced projections to several non-image-forming areas: OPN (63\% reduction), PPN (54\% reduction), IGL ( $49 \%$ reduction), and vLGN (42\% reduction; Fig. $5 A-D$ ). Projections to the dLGN, NOT (Fig. 5A-D), SC, MTN, and SCN (Fig. 5E-J) were not significantly different. This loss of inputs only in specific nuclei is consistent with the hypothesis that Tbr2 is required for the formation or survival of RGC types, including ipRGCs, which participate in non-image-forming visual circuits. Although ipRGCs account for almost all SCN input from the retina, the unchanged projection in the Tbr2 conditional mutant could reflect the remaining melanopsin ${ }^{+}$RGCs with M1-type laminations (Güler et al., 2007; Chen et al., 2011).

To verify that these phenotypes were due to loss of Tbr2 in the retina, we stained $\mathrm{P} 1$ brains for Tbr2 in retinal targets and found no Tbr2 ${ }^{+}$cells in the OPN, IGL, LGN, or PPN; however, consistent with previous reports (Bulfone et al., 1999; Kimura et al., 1999), labeled cells were found in the hippocampus (data not shown).

Tbr2 conditional knockouts show reduced pupillary response Pupil constriction regulates the amount of light entering the eye and pupil diameter is negatively correlated with light intensity. In bright light, the mouse iris can decrease the pupil area by as much as $95 \%$ (full constriction) compared with dark-adapted conditions (fully dilated; Chen et al., 2011). When Tbr2 is removed from the developing retina using the $C B 2$ Cre line, we find that these mice have a significant defect of the pupillary light reflex at both high and low light intensities for the contralateral (Fig. 6) and ipsilateral eyes (data not shown). We hypothesize that the remaining pupillary response is due to the $32 \%$ of $\mathrm{Tbr}{ }^{+}$RGCs being spared by the CB2-Cre line, leaving some innervation of the OPN (Fig. $5 C$ ). Nonetheless, this demonstrates that, consistent with the loss of RGC inputs, retinal Tbr2 is required for a light-induced behavior and is likely to be involved in other nonspatial, light-dependent behaviors.

\section{Discussion}

Due to its accessibility, long history of study, and insights it can lend to human perception, the mouse retina serves as an ideal CNS structure with which to study the development of neuronal cell types and their roles in information processing by neural circuits. The retina performs a wide range of visual processing, including motion detection, color discrimination, and adaptation to changes in light levels; all of this is accomplished using parallel circuits to process and transfer specific aspects of the visual world. At the output of each retinal circuit, a unique type of RGC sends information about a specific aspect of the visual scene to the brain. What remain largely unknown are the genetic and environmental factors that create complex visual circuitry during development and how each visual pathway contributes to perception. Here, we identify the transcription factor Tbr2 as being necessary for the development of a subset of RGC types that target non-image-forming areas. Knockout of Tbr2 in RGCs during development leads to a decrease in Tbr $2{ }^{+}$RGCs and selective loss of axonal projections to non-image-forming nuclei. As a consequence, the pupillary light reflex is attenuated and this completes the link between mutation of a transcription factor during retinal development and a deficit in a light-induced adult behavior.

\section{Tbr2 is expressed selectively in RGC types that project to non- image-forming targets}

Previous studies have shown that Tbr2 is expressed downstream of Brn3b in developing RGCs and that loss of Tbr2 during retinal development leads to an increase in apoptosis of RGCs (Mao et al., 2008). Here, we extend this finding by characterizing Tbr ${ }^{+}$ RGCs and identifying their common projections to targets involved in non-image-forming behaviors. Tbr ${ }^{+}$RGC types include M1-M3 ipRGC types (Ecker et al., 2010), those expressing GFP in the Cdh3-GFP BAC line (Osterhout et al., 2011), those expressing the netrin receptor Unc5d, and those labeled in neither the Cdh3-GFP line nor by melanopsin or Unc5d antibodies.

Both melanopsin ${ }^{+}$ipRGCs and Cdh3-GFP RGCs primarily project axons to non-image-forming retinorecipient areas in the thalamus and midbrain and have dendrites that project to discrete IPL laminae. Some M1 ipRGCs project to the SCN $\left(\mathrm{Brn} 3 \mathrm{~b}^{-}\right)$and others to the OPN shell $\left(\mathrm{Brn} 3 \mathrm{~b}^{+}\right)$, whereas the M2, M4, and M5 types project to the OPN core and to the imageforming dLGN and SC (Schmidt et al., 2011). ipRGC dendrites target the OFF (M1), ON (M2, M4, and M5), and both ON and OFF sublaminae (M3). Cdh3-GFP RGCs express Cadherin-6, 
which contributes to target selection efficiency, and consist of two morphological types: one with radial, sparse branches and one with asymmetric, dense arbors. Some Cdh3-GFP RGCs project to the ON sublamina and others project to both ON and OFF sublaminae (Osterhout et al., 2011). Based on Tbr2 being expressed in ipRGCs and Cdh3-GFP RGCs (18\% and 9\% of total Tbr $2^{+}$RGCs, respectively), we can conclude that at least $27 \%$ of $\mathrm{Tbr} 2{ }^{+}$RGCs project to non-image-forming targets.

To examine the projections of the remaining Tbr $2^{+}$RGCs, we used the Tbr2-GFP line and found $\mathrm{GFP}^{+}$axons only in nonimage-forming areas. A caveat is that this line does not fully recapitulate the endogenous Tbr2 expression; all Tbr2-GFP RGCs express Tbr2, but only $6 \%$ of the Tbr $2^{+}$RGCs express Tbr2-GFP. We cannot be sure that this $6 \%$ includes each Tbr2 ${ }^{+}$RGC type and melanopsin ${ }^{+}$RGCs are likely overrepresented; however, we do find both melanopsin ${ }^{+}$and melanopsin ${ }^{-}$RGCs within the Tbr2-GFP class. Although we cannot discern whether the Tbr2$\mathrm{GFP}^{+} /$melanopsin ${ }^{-}$cells represent all $\mathrm{Tbr} 2^{+}$types, we do not find Tbr2 expressed in RGC types known to project exclusively to image-forming areas such as direction-selective RGCs (labeled by anti-CART and in the DRD4-GFP line) or Islet $2^{+}$RGCs. Moreover, Tbr2-expressing RGCs were largely distinct from those expressing Brn3a, and all of the Tbr2-negative subtypes that we examined expressed Brn3a. Brn3a ${ }^{+}$RGCs have been shown previously to avoid all (Quina et al., 2005) or some (Badea et al., 2009) non-image-forming areas. These results are all consistent with the hypothesis that Tbr2 plays a primary role in development of the majority, and probably the entirety, of a non-imageforming RGC lineage.

\section{Tbr2 is required for the development of RGC types that project to non-image-forming areas}

It has been shown previously that removing Tbr2 from a subset of retinal progenitors using the Six3-Cre line caused mice to have increased apoptosis in RGCs during both embryonic and early postnatal periods; however, it remained to be seen whether this death was restricted to a specific type(s) of RGC (Mao et al., 2008). Here, we show that the removal of Tbr2 from the developing retina using CB2-Cre leads to a loss of melanopsin ${ }^{+}$, Cdh3GFP, and Unc5 $\mathrm{d}^{+}$RGC types and decreased innervation of specific non-image-forming retinorecipient nuclei. $T b r 2^{\text {fllfl }}$; $\mathrm{CB}^{\mathrm{Cre} /+}$ mice have diminished axonal projections to the vLGN, IGL, OPN, and PPN, but do not show decreased retinal input to the dLGN, SC, NOT, MTN, or SCN, which is consistent with Tbr2 being required for the formation and/or survival of Tbr $2^{+}$ RGCs, but not other RGCs.

These data also point to Tbr2 ${ }^{+}$RGCs as the main source of retinal innervation to several non-image-forming nuclei. Although some inputs into these areas persist in the conditional knockout, this is likely due to the incomplete penetrance of the CB2-Cre line, which expresses Cre in $56 \%$ of early postnatal Tbr2 ${ }^{+}$RGCs. Although difficult to quantify precisely, we estimate that $37 \%$ of inputs to the OPN in Tbr 2 conditional mutants remain (using fluorescence intensity as a measurement). This is approximately the same proportion of Tbr $2{ }^{+}$RGCs that remain in conditional mutants, suggesting that $\mathrm{Tbr} 2{ }^{+} \mathrm{RGCs}$ comprise the primary OPN input. As for the retinal projection to the SCN, the lack of anatomical phenotype could indicate that the remaining M1-like ipRGCs include many SCN-projecting M1/Brn3b ${ }^{-}$ ipRGCs (Chen et al., 2011). Further work will use Cre lines with more widespread expression in the retina to determine the complete extent of Tbr2 knockout phenotypes.

\section{Tbr2 is required for a normal pupillary light reflex}

In mammals, there are a number of distinct non-image-forming areas that contribute to light-induced subconscious behaviors. Consistent with a reduction of OPN inputs, $\mathrm{Tbr}^{\mathrm{fl} / \mathrm{fl}} ; \mathrm{CB}^{\mathrm{Cre} /+}$ mice show an attenuated, but not absent, pupillary light reflex. The remaining response could be due to the $21 \%$ of ipRGCs that are spared in the mutant, because previous work has found that ipRGCs account for most of the required inputs for this behavior (Güler et al., 2007). The degree to which melanopsin ${ }^{-} / \mathrm{Tbr}^{+}{ }^{+}$RGCs contribute to the pupillary light reflex remains to be determined.

In conclusion, this study completes a link between the expression of a transcription factor in a neuron, the development of a circuit that contains that neuron, and the contribution of that circuit to behavior. The identification of a requirement for Tbr2 in RGC types that control non-image-forming behaviors is an important step in understanding the transcriptional code that generates RGC specificity and diversity.

\section{References}

Arnold SJ, Huang GJ, Cheung AF, Era T, Nishikawa S, Bikoff EK, Molnár Z Robertson EJ, Groszer M (2008) The T-box transcription factor Eomes/ Tbr2 regulates neurogenesis in the cortical subventricular zone. Genes Dev 22:2479-2484. CrossRef Medline

Badea TC, Cahill H, Ecker J, Hattar S, Nathans J (2009) Distinct roles of transcription factors brn3a and brn3b in controlling the development, morphology, and function of retinal ganglion cells. Neuron 61:852-864. CrossRef Medline

Berson DM (2008) Retinal ganglion cell types and their central projections. In: The senses: a comprehensive reference (Basbaum A, Shepherd G, Westheimer G, eds), pp 491-520. San Diego: Academic.

Berson DM, Dunn FA, Takao M (2002) Phototransduction by retinal ganglion cells that set the circadian clock. Science 295:1070-1073. CrossRef Medline

Brown NL, Patel S, Brzezinski J, Glaser T (2001) Math5 is required for retinal ganglion cell and optic nerve formation. Development 128:24972508. Medline

Bulfone A, Martinez S, Marigo V, Campanella M, Basile A, Quaderi N, Gattuso C, Rubenstein JL, Ballabio A (1999) Expression pattern of the Tbr2 (Eomesodermin) gene during mouse and chick brain development. Mech Dev 84:133-138. CrossRef Medline

Chalupa LM, Günhan E (2004) Development of On and Off retinal pathways and retinogeniculate projections. Prog Retin Eye Res 23:31-51. CrossRef Medline

Chen SK, Badea TC, Hattar S (2011) Photoentrainment and pupillary light reflex are mediated by distinct populations of ipRGCs. Nature 476:92-95. CrossRef Medline

Coombs JL, Van Der List D, Chalupa LM (2007) Morphological properties of mouse retinal ganglion cells during postnatal development. J Comp Neurol 503:803-814. CrossRef Medline

Dhande OS, Estevez ME, Quattrochi LE, El-Danaf RN, Nguyen PL, Berson DM, Huberman AD (2013) Genetic dissection of retinal inputs to brainstem nuclei controlling image stabilization. J Neurosci 33:17797-17813. CrossRef Medline

Ecker JL, Dumitrescu ON, Wong KY, Alam NM, Chen SK, LeGates T, Renna JM, Prusky GT, Berson DM, Hattar S (2010) Melanopsin-expressing retinal ganglion-cell photoreceptors: cellular diversity and role in pattern vision. Neuron 67:49-60. CrossRef Medline

Fu Y, Liao HW, Do MT, Yau KW (2005) Non-image-forming ocular photoreception in vertebrates. Curr Opin Neurobiol 15:415-422. CrossRef Medline

Giolli RA, Blanks RHI, Lui F (2006) The accessory optic system: basic organization with an update on connectivity, neurochemistry, and function. In: Progress in brain research (Büttner-Ennever JA, ed), pp 407-440. Amsterdam: Elsevier.

Gong S, Zheng C, Doughty ML, Losos K, Didkovsky N, Schambra UB, Nowak NJ, Joyner A, Leblanc G, Hatten ME, Heintz N (2003) A gene expression atlas of the central nervous system based on bacterial artificial chromosomes. Nature 425:917-925. CrossRef Medline

Güler AD, Altimus CM, Ecker JL, Hattar S (2007) Multiple photoreceptors 
contribute to nonimage-forming visual functions predominantly through melanopsin-containing retinal ganglion cells. Cold Spring Harb Symp Quant Biol 72:509-515. CrossRef Medline

Harrington ME (1997) The ventral lateral geniculate nucleus and the intergeniculate leaflet: interrelated structures in the visual and circadian systems. Neurosci Biobehav Rev 21:705-727. CrossRef Medline

Hattar S, Liao HW, Takao M, Berson DM, Yau KW (2002) Melanopsincontaining retinal ganglion cells: architecture, projections, and intrinsic photosensitivity. Science 295:1065-1070. CrossRef Medline

Huberman AD, Manu M, Koch SM, Susman MW, Lutz AB, Ullian EM, Baccus SA, Barres BA (2008) Architecture and activity-mediated refinement of axonal projections from a mosaic of genetically identified retinal ganglion cells. Neuron 59:425-438. CrossRef Medline

Huberman AD, Wei W, Elstrott J, Stafford BK, Feller MB, Barres BA (2009) Genetic identification of an On-Off direction-selective retinal ganglion cell subtype reveals a layer-specific subcortical map of posterior motion. Neuron 62:327-334. CrossRef Medline

Jiang Y, Ding Q, Xie X, Libby RT, Lefebvre V, Gan L (2013) Transcription factors SOX4 and SOX11 function redundantly to regulate the development of mouse retinal ganglion cells. J Biol Chem 288:18429-18438. CrossRef Medline

Kimura N, Nakashima K, Ueno M, Kiyama H, Taga T (1999) A novel mammalian T-box-containing gene, Tbr2, expressed in mouse developing brain. Brain Res Dev Brain Res 115:183-193. CrossRef Medline

Luo L, Callaway EM, Svoboda K (2008) Genetic dissection of neural circuits. Neuron 57:634-660. CrossRef Medline

Mao CA, Kiyama T, Pan P, Furuta Y, Hadjantonakis AK, Klein WH (2008) Eomesodermin, a target gene of Pou $4 \mathrm{f} 2$, is required for retinal ganglion cell and optic nerve development in the mouse. Development 135:271280. Medline

Masland RH (2012) The neuronal organization of the retina. Neuron 76: 266-280. CrossRef Medline

MuX, Klein WH (2004) A gene regulatory hierarchy for retinal ganglion cell specification and differentiation. Semin Cell Dev Biol 15:115-123. CrossRef Medline

Nelson SB, Hempel C, Sugino K (2006) Probing the transcriptome of neuronal cell types. Curr Opin Neurobiol 16:571-576. CrossRef Medline

Osterhout JA, Josten N, Yamada J, Pan F, Wu SW, Nguyen PL, Panagiotakos G, Inoue YU, Egusa SF, Volgyi B, Inoue T, Bloomfield SA, Barres BA, Berson DM, Feldheim DA, Huberman AD (2011) Cadherin-6 mediates axon-target matching in a non-image-forming visual circuit. Neuron 71: 632-639. CrossRef Medline

Pak W, Hindges R, Lim YS, Pfaff SL, O’Leary DD (2004) Magnitude of binocular vision controlled by islet- 2 repression of a genetic program that specifies laterality of retinal axon pathfinding. Cell 119:567-578. CrossRef Medline

Pérez De Sevilla Müller L, Shelley J, Weiler R (2007) Displaced amacrine cells of the mouse retina. J Comp Neurol 505:177-189. CrossRef Medline

Provencio I, Rollag MD, Castrucci AM (2002) Photoreceptive net in the mammalian retina. This mesh of cells may explain how some blind mice can still tell day from night. Nature 415:493. CrossRef Medline

Quina LA, Pak W, Lanier J, Banwait P, Gratwick K, Liu Y, Velasquez T, O'Leary DD, Goulding M, Turner EE (2005) Brn3a-expressing retinal ganglion cells project specifically to thalamocortical and collicular visual pathways. J Neurosci 25:11595-11604. CrossRef Medline

Russ AP, Wattler S, Colledge WH, Aparicio SA, Carlton MB, Pearce JJ, Barton SC, Surani MA, Ryan K, Nehls MC, Wilson V, Evans MJ (2000) Eomesodermin is required for mouse trophoblast development and mesoderm formation. Nature 404:95-99. CrossRef Medline

Schmidt TM, Chen SK, Hattar S (2011) Intrinsically photosensitive retinal ganglion cells: many subtypes, diverse functions. Trends Neurosci 34 : 572-580. CrossRef Medline

Sessa A, Mao CA, Hadjantonakis AK, Klein WH, Broccoli V (2008) Tbr2 directs conversion of radial glia into basal precursors and guides neuronal amplification by indirect neurogenesis in the developing neocortex. Neuron 60:56-69. CrossRef Medline

Shirasaki R, Pfaff SL (2002) Transcriptional codes and the control of neuronal identity. Annu Rev Neurosci 25:251-281. CrossRef Medline

Triplett JW, Wei W, Gonzalez C, Sweeney NT, Huberman AD, Feller MB, Feldheim DA (2014) Dendritic and axonal targeting patterns of a genetically-specified class of retinal ganglion cells that participate in image-forming circuits. Neural Develop 9:2. CrossRef Medline

Wässle H (2004) Parallel processing in the mammalian retina. Nat Rev Neurosci 5:747-757. CrossRef Medline

Xiang M, Zhou L, Macke JP, Yoshioka T, Hendry SH, Eddy RL, Shows TB, Nathans J (1995) The Brn-3 family of POU-domain factors: primary structure, binding specificity, and expression in subsets of retinal ganglion cells and somatosensory neurons. J Neurosci 15:4762-4785. Medline

Zhu Y, Ju S, Chen E, Dai S, Li C, Morel P, Liu L, Zhang X, Lu B (2010) T-bet and eomesodermin are required for $\mathrm{T}$ cell-mediated antitumor immune responses. J Immunol 185:3174-3183. CrossRef Medline 